\title{
Adapting community-focused writing support for researchers to synchronous online delivery
}

\author{
Nicola Grayson \\ University of Manchester, UK \\ Anna Theis \\ University of Manchester, UK
}

Keywords: community; research; synchronous; asynchronous; writing; Covid-19.

\section{The challenge}

Prior to March 2020, My Research Essentials (MRE), the University of Manchester (UoM) Library's researcher development programme followed a blended offer of face-to-face and online support. Creating a sense of community has always been at the heart of the MRE programme's pedagogical approach (see Grayson and Napthine-Hodgkinson, 2020) and the problems faced by our core audience (postgraduate researchers (PGRs)) have been well-documented (see (Thomson, 2020)). MRE was built on a philosophy designed to combat feelings of imposter syndrome and isolation by encouraging researchers to work together and envisage themselves as part of a research community (Beauvoir, 1963).

At the start of the pandemic, most of the UoM's immediate response was geared towards undergraduates. A survey of PGRs revealed worries about finances, difficulties conducting research, and the impact of the pandemic on completion. PGRs reported struggling with increased amounts of stress as family members fell ill (or died) and for those with additional caring responsibilities it was hard to find time to write, even when they felt able to. The first stage of our challenge, therefore, was how to reach our audience and retain the MRE's integral focus on creating a sense of community when we had to operate in a virtual space.

The UoM Library set up a Virtual Teaching Group (VTG) to ensure a unified approach across its learning programmes. Its objective was to provide guidance to address the 
needs and demands of learners, and to advocate an approach which recognises that there are challenges and barriers to accessing online support, e.g., different time zones and access to technology (see our VTG blog post to find out more: Virtual Teaching and Support. An approach developed by Teaching... | by Library for Educators | Medium). The VTG worked with pedagogical guidance from critical educator Jesse Stommel who outlined an approach to online teaching and support very early on in the pandemic:

[At] this moment, we should start by designing for the least privileged, most marginalized students, the ones with the least access [...] We have to build for asynchronous, design real points of entry for students who can't be physically present at a particular time or in specific ways (Stommel, 2020).

The second stage of our challenge concerned how to negotiate a tension between responding to the unique demands of our research audience (who needed time and space to connect) whilst ensuring parity of access to resources through an emphasis on asynchronous support. We wanted to retain our community focused approach and trial 'live' sessions, but we needed to ensure the support we offered was inclusive and open to all in the manner outlined above.

\section{The response}

We volunteered our Shut Up and Write (SUAW) sessions as a case study for the VTG citing these sessions as an example of where a synchronous element was necessary, in line with MRE's community focused approach. Before the pandemic, face-to-face SUAWs were run by our Student Team (paid student members of staff, some of whom are PGR) to utilise peer-to-peer support. During the pandemic, we used insights from our Student Team to gain a sense of what was specifically needed (and not needed) for synchronous support. Members of the team had attended a variety of online events quite early on and they helped us frame our support appropriately so that we did not put pressure on researchers to be productive but instead sought to offer an online space where attendees could carve out time to focus and connect with and support one another. We used their experiences to word our offer carefully. 
Using SUAW as a case study allowed us to trial online, synchronous delivery and to reconnect with our audience. It meant we could let researchers know that we were still here for them, assess their current needs and signpost them to further support, and they could connect with one another to positively reinforce their identity as part of a research community.

During the pilots we regularly reviewed attendance and feedback data (from surveys) and recorded anecdotal feedback. We used this to adapt the sessions as required so that the support was iterative and relevant. The pilot sessions gave us the flexibility to do this so that we could then take SUAW back to the VTG and report on what worked, the challenges, the amount of resources required, and what we might change going forwards. The pilots were a success; we were able to demonstrate that community-focused, 'live' support was needed and that we could run it a considered, inclusive way across the Library's other programmes.

To ensure that support was available for those who could not attend live sessions we set up an MRE blog (My Research Essentials - Medium). We worked with the Student Team to create a SUAW post outlining the rationale behind the sessions and the strategies we use (Introducing Online Shut up and write sessions | by MRE Blog | My Research Essentials | Medium). We updated this so that our audience could benefit from any tips and signposting that occurred in the live sessions. We also varied the times and dates of live sessions to build flexibility into our schedule and changed our administrative processes so that pre- and post-session emails linked to and highlighted the asynchronous support.

Our approach influenced writing support delivered through the UoM's Centre for Academic and Researcher Development (CARD) and we agreed to deliver support on alternate weeks, working in partnership to cross-promote each other so that researchers always had access to their community and the chance for focused writing time. The careful language we used (which emphasised connection over productivity) was utilised for many other events and our emphasis on creating a sense of community inspired the creation of a series of 'Together' sessions run by our multi-award-winning sister programme (My Learning Essentials) which are aimed at a much wider audience. 


\section{Recommendations}

The pilot SUAWs were very well attended, and attendees have asked us to continue offering them online going forwards. Running the sessions as pilots enabled us to demonstrate that 'live' teaching could be offered in an inclusive way if it is accompanied by (and informs the creation of) asynchronous support. The pilot-status allowed us the flexibility to try things out and adapt sessions based on our experiences and attendee feedback.

It was useful to combine our experiences with CARD and to work with PGRs both in our Student Team and in the sessions to gain a holistic understanding of the impact the pandemic was having on our audience. We actively encouraged them to shape the support so that it was relevant to the ever-changing climate, and we could create a better experience for our attendees. Co-creating the synchronous and asynchronous support with the Student Team was integral; they helped us to frame it effectively, they reviewed data, shared advice, co-delivered sessions, and recorded feedback to ensure that researchers' current needs were being addressed.

We learnt that you need to advocate for your audience whilst aligning with best practice in relation to inclusivity and accessibility. We knew that researchers needed to connect and that live sessions might offer them a space to do this, but we had to ensure that those who could not attend had equal access to support and advice. Our key take-away message is that online synchronous sessions need to be accompanied by asynchronous supporting resources to ensure inclusivity and access for all. This way, those who cannot attend live sessions can still benefit from the content discussed and from knowing that they have been carefully considered as an equally important part of the community.

\section{References}

Beauvoir, S. de. (1963) Memoirs of a dutiful daughter. Harmondsworth: Penguin. 
Grayson, N. J., Blake, J. and Stock, M. (2018) 'The co-creation of exam support: students as partners in the research, planning, design and quality assurance of learning resources', Journal of Educational Innovation, Partnership and Change, 4(1). https://doi.org/10.21100/jeipc.v4i1.767.

Grayson, N. and Napthine-Hodgkinson, J. (2020) 'How improvisation techniques can support researchers with the development of public speaking skills', Journal of Learning Development in Higher Education, Issue 19, December, pp.1-17. https://doi.org/10.47408/jldhe.vi19.611.

Stommel, J. [@Jessifer] (2020). 'A static recording of a synchronous Zoom conversation doesn't really count as "asynchronous" learning...' [Twitter] 21 May. Available at: https://twitter.com/Jessifer/status/1263579427088162816 (Accessed: 10 June 2021).

Thomson, B. (2020) 'It's now beyond doubt: we need to reimagine the way research works', Wellcome. Available at: https://wellcome.org/news/its-now-beyond-doubtwe-need-reimagine-way-research-works (Accessed: 10 June 2021).

University of Manchester Library Student Team (2020) 'Introducing Online Shut up and write sessions', Medium. Available at: https://medium.com/my-researchessentials/introducing-online-shut-up-and-write-sessions-c4c5baa7be8f (Accessed: 10 June 2021).

University of Manchester Library Teaching, Learning and Students Team (2020) 'Virtual Teaching and Support', Medium. Available at: https://foreducators.medium.com/virtual-teaching-and-support-1be25054a7f (Accessed: 10 June 2021).

\section{Author Details}

Nicola Grayson is a Learning Developer at the University of Manchester and works as a Lecturer in Philosophy at Manchester Metropolitan University. She joined the editorial 
board of the Journal of Learning Development in Higher Education in 2020. Her areas of expertise include widening access to education, researcher development, and measuring the impact of learning interventions. Nicola has a Postgraduate Certificate in Higher Education and is a Senior Fellow of the Higher Education Academy. She is passionate about the pursuit of knowledge and supporting others on their learning journey.

Anna Theis is a librarian at the University of Manchester. She teaches across the Library's teaching programmes and her areas of expertise include information literacy, researcher development, and facilitating peer learning. Anna manages the Library's Student Team ensuring that the student voice is incorporated across library services. Anna is a Fellow of the Higher Education Academy and an active member of the Chartered Institute of Library and Information Professionals. As a committee member she runs events for the Academic and Research Libraries North West members' network. 